\title{
Aedes aegypti has spatially structured and seasonally stable populations in Yogyakarta, Indonesia
}

Gordana Rašić, Nancy Endersby-Harshman', Warsito Tantowijoyo², Anjali Goundar', Vanessa White', Qiong Yang ', Igor Filipović ${ }^{1}$ Petrina Johnson ${ }^{3}$, Ary A. Hoffmann ${ }^{1 *}$ and Eggi Arguni ${ }^{2}$

\begin{abstract}
Background: Dengue fever, the most prevalent global arboviral disease, represents an important public health problem in Indonesia. Control of dengue relies on the control of its main vector, the mosquito Aedes aegypti, yet nothing is known about the population history and genetic structure of this insect in Indonesia. Our aim was to assess the spatio-temporal population genetic structure of Ae. aegypti in Yogyakarta, a densely populated region on Java with common dengue outbreaks.

Methods: We used multiple marker systems (microsatellites, nuclear and mitochondrial genome-wide single nucleotide polymorphisms generated via Restriction-site Associated DNA sequencing) to analyze 979 Ae. aegypti individuals collected from the Yogyakarta city and the surrounding hamlets during the wet season in 2011 and the following dry season in 2012. We employed individual- and group-based approaches for inferring genetic structure.

Results: We found that Ae. aegypti in Yogyakarta has spatially structured and seasonally stable populations. The spatial structuring was significant for the nuclear and mitochondrial markers, while the temporal structuring was non-significant. Nuclear markers identified three main genetic clusters, showing that hamlets have greater genetic isolation from each other and from the inner city sites. However, one hamlet experienced unrestricted mosquito interbreeding with the inner city, forming a single genetic cluster. Genetic distance was poorly correlated with the spatial distance among mosquito samples, suggesting stronger influence of human-assisted gene flow than active mosquito movement on spatial genetic structure. A star-shaped mitochondrial haplotype network and a significant $R^{2}$ test statistic $\left(R^{2}=0.0187, P=0.001\right)$ support the hypothesis that $A$ e. aegypti in Yogyakarta originated from a small or homogeneous source and has undergone a relatively recent demographic expansion.
\end{abstract}

Conclusion: We report the first insights into the spatio-temporal genetic structure and the underlying processes in the dengue fever mosquito from Yogyakarta, Indonesia. Our results provide valuable information on the effectiveness of local control measures as well as guidelines for the implementation of novel biocontrol strategies such as release of Wolbachia-infected mosquitoes.

Keywords: Aedes aegypti, Dengue, Indonesia, Genetic structure, RADseq, Microsatellites, mtDNA

\footnotetext{
* Correspondence: ary@unimelb.edu.au

Gordana Rašić and Nancy Endersby-Harshman are joint first authors. Ary A.

Hoffmann and Eggi Arguni are joint senior authors.

${ }^{1}$ School of BioSciences, Bio21 Institute, The University of Melbourne,

Melbourne, VIC 3010, Australia

Full list of author information is available at the end of the article
}

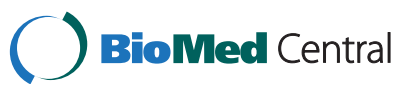

C 2015 Rašić et al. Open Access This article is distributed under the terms of the Creative Commons Attribution 4.0 nternational License (http://creativecommons.org/licenses/by/4.0/), which permits unrestricted use, distribution, and reproduction in any medium, provided you give appropriate credit to the original author(s) and the source, provide a link to the Creative Commons license, and indicate if changes were made. The Creative Commons Public Domain Dedication waiver (http://creativecommons.org/publicdomain/zero/1.0/) applies to the data made available in this article, unless otherwise stated. 


\section{Background}

Dengue fever is the most prevalent arboviral disease in the world and Indonesia boasts one of the highest numbers of dengue infections amongst the most endemic nations [1]. Moreover, incidence of a severe disease form known as the dengue hemorrhagic fever has dramatically increased in Indonesia over the past 45 years [2]. A surge in dengue outbreaks is attributed to a combination of factors such as rapid human population growth, migration from rural to urban areas, inadequate basic urban infrastructure and public health measures [3], all of which favor viral transmission by the main vector Aedes aegypti. This mosquito has a close association with human habitation, preferentially exploiting domestic environments for its feeding and breeding requirements [4-6].

Given that an effective vaccines or treatments against dengue viruses are not yet available, the control of dengue transmission is mostly dependent on the control of the vector populations [1]. Insecticide applications remain the predominant strategy to control the dengue fever mosquito, but their extensive and inappropriate use has led to a development of insecticide resistance in Ae. aegypti populations around the world, including Indonesia [7, 8]. In the last 15 years, a significant advancement has been made in developing and implementing alternative strategies to overcome the limitation of traditional measures and to achieve a sustainable control of vector populations [9]. One such strategy involves the use of the intracellular bacterium Wolbachia pipientis that has been artificially transferred into Ae. aegypti $[10,11]$. Wolbachia infection induces a number of pathogen-resistant phenotypes that reduce the mosquito's vectorial competency [12]. This strategy is based on the releases of Wolbachia-infected Ae. aegypti into the field to replace the vector competent populations with mosquitoes that have a significantly diminished capacity for pathogen transmission [13-15].

Following the successful Wolbachia releases in northern Australia and Vietnam $[15,16]$, the implementation of this strategy is planned for the region of Yogyakarta (http://www.eliminatedengue.com/indonesia). Given that the establishment and spread of Wolbachia infection is influenced by the dynamics of local populations as well as migration among them $[17,18]$, it is essential to obtain knowledge of the population genetic structure and gene flow in Ae. aegypti throughout Yogyakarta.

Apart from information on the strong genome-wide differentiation between a small sample of Ae. aegypti from Indonesia and samples from Vietnam, Australia and Brazil [19], there is no knowledge on the population genetic structure in the dengue fever mosquito from Indonesia. Studies from other countries in southeast Asia have generally shown significant population structuring for a range of spatial scales (5 to $>2000 \mathrm{~km}$ ) [20]. However, the level of genetic structuring was highly variable among areas with different levels of urbanization (rural vs. urban) or between seasons (rainy vs. dry) (reviewed in [21]).

Here, our aim was to assess the spatio-temporal population genetic structure of Ae. aegypti in the city of Yogyakarta and the surrounding hamlets. This large and densely populated urban environment on the island of Java with an approximate population of 3.4 million people has common dengue outbreaks [22]. For example, an average annual rate of 16.8 dengue cases per 10,000 inhabitants has been reported in Yogyakarta city from 2005 to 2007 (Yogyakarta City Health Office, 2008). We used several types of genetic marker (microsatellites, nuclear and mitochondrial genome-wide single nucleotide polymorphisms) to genotype individuals of Ae. aegypti collected during one wet and one dry season. We considered the following questions: 1) what is the level of structuring at the nuclear and mitochondrial genomes among sites in Yogyakarta? 2) Is there a seasonal variation in genetic structuring? 3) Is the level of gene flow different among urban and suburban areas (i.e. Yogyakarta city and hamlets)?

\section{Methods \\ Sampling}

Thirteen collection sites within three districts were established in the Special Region of Yogyakarta for this study (Fig. 1, Table 1). Samples were collected from the districts of Bantul and Sleman between October to December of 2011 as a representation of the wet season and in July of 2012 as a representation of the dry season. The average precipitation in Yogyakarta in July is $40 \mathrm{~mm}$ and increases to $90-340 \mathrm{~mm}$ in October to December. The sites are separated by areas of agricultural land with many large roads/ highways and rivers/canals which are likely to impede mosquito dispersal. Dry season samples also included a collection made in November 2012 from the City of Yogyakarta (Fig. 1, sites 11-13), allowing for the study of mosquito population structure between continuously populated sites without the agricultural lands. The area covered by districts Sleman, Yogyakarta City and Bantul is approximately $1,115.45 \mathrm{~km} 2$ with each collection site spanning between $0.1 \mathrm{~km}^{2}$ and $1.0 \mathrm{~km}^{2}$.

Within each collection site, Aedes aegypti larvae and adults were collected from ovitraps and backpack aspirators (BPA) positioned inside or very close to the houses (i.e. front- or backyards). Eggs collected from ovitraps were reared to the third larval instar to facilitate identification of species. A single larva from each ovitrap was used for analysis to minimise sampling of family groups $[19,23,24]$, while multiple adults from each house were sampled and analysed. 


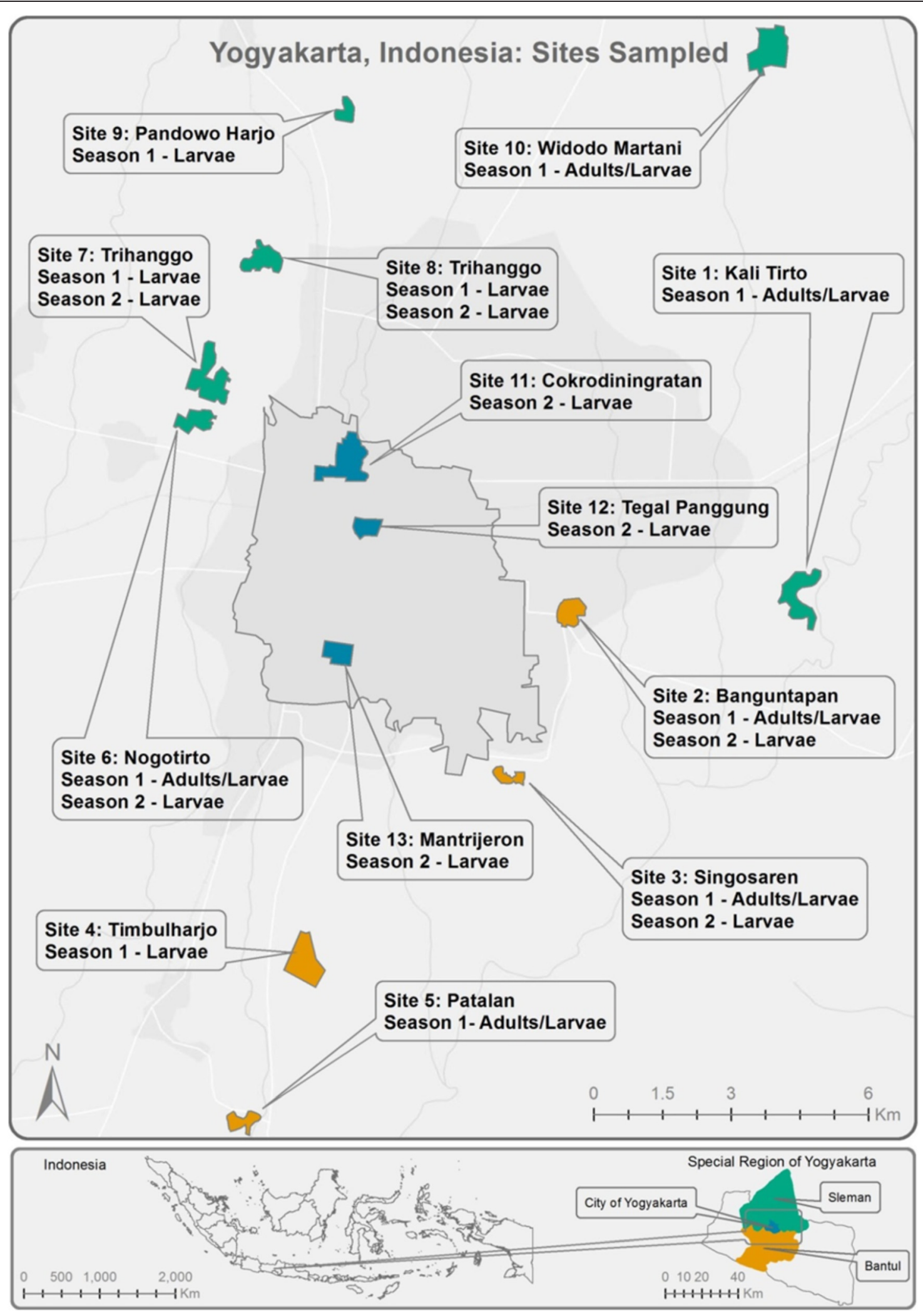

Fig. 1 Collection sites in Yogyakarta region in central Java, Indonesia. Aedes aegypti adults and larvae were sampled in the wet season in 2011 and in the following dry season in 2012. The inner city area (with sites 11-13) is delineated with a border line 
Table 1 Indices of population genetic diversity for Aedes aegypti in Yogyakarta, Indonesia

\begin{tabular}{|c|c|c|c|c|c|c|c|c|c|c|c|c|}
\hline \multirow[b]{2}{*}{ Site } & \multirow[b]{2}{*}{ Hamlet } & \multirow[b]{2}{*}{ Life stage/season } & \multicolumn{4}{|c|}{ Microsatellites } & \multicolumn{3}{|c|}{ nuclear SNPs } & \multicolumn{3}{|c|}{ mtDNA } \\
\hline & & & $n$ & Allelic richness & $H_{E}$ & $F_{I S}$ & $n$ & $H_{\mathrm{E}}$ & $F_{I S}$ & $n$ & $\pi$ & $\mathrm{Hd}$ \\
\hline \multirow[t]{2}{*}{1} & Kali Tirto & L/wet & 52 & 3.99 & 0.532 & 0.020 & - & - & - & - & - & - \\
\hline & & A/wet & 21 & 3.87 & 0.506 & 0.138 & - & - & - & - & - & - \\
\hline \multirow[t]{3}{*}{2} & Banguntapan & L/wet & 79 & 4.54 & 0.614 & 0.069 & - & - & - & - & - & - \\
\hline & & L/dry & 34 & 5.81 & 0.597 & 0.055 & 9 & 0.210 & 0.157 & 19 & 0.0009 & 0.713 \\
\hline & & A/wet & 27 & 5.31 & 0.607 & -0.010 & - & - & - & - & - & - \\
\hline \multirow[t]{3}{*}{3} & Singosaren & L/wet & 23 & 4.44 & 0.560 & 0.132 & - & - & - & - & - & - \\
\hline & & L/dry & 36 & 5.26 & 0.553 & 0.169 & 5 & 0.209 & -0.011 & 15 & 0.0013 & 0.819 \\
\hline & & A/wet & 30 & 5.05 & 0.598 & 0.083 & - & - & - & - & - & - \\
\hline 4 & Timbulharjo & L/wet & 16 & 3.81 & 0.569 & 0.005 & - & - & - & - & - & - \\
\hline \multirow[t]{2}{*}{5} & Patalan & L/wet & 17 & 4.25 & 0.549 & 0.164 & - & - & - & - & - & - \\
\hline & & A/wet & 23 & 4.64 & 0.547 & 0.035 & - & - & - & - & - & - \\
\hline \multirow[t]{3}{*}{6} & Nogotirto & L/wet & 34 & 4.13 & 0.583 & 0.044 & 10 & 0.205 & 0.077 & 6 & 0.0044 & 0.800 \\
\hline & & L/dry & 37 & 5.14 & 0.593 & 0.073 & 12 & 0.207 & 0.051 & 9 & 0.0012 & 0.694 \\
\hline & & A/wet & 27 & 4.30 & 0.522 & 0.030 & - & - & - & - & - & - \\
\hline \multirow[t]{2}{*}{7} & Trihanggo & L/wet & 46 & 3.89 & 0.522 & 0.055 & 16 & 0.214 & 0.051 & 10 & 0.0012 & 0.533 \\
\hline & & L/dry & 36 & 5.17 & 0.523 & 0.035 & 12 & 0.217 & 0.107 & 9 & 0.0007 & 0.250 \\
\hline \multirow[t]{2}{*}{8} & Trihanggo & L/wet & 30 & 3.86 & 0.547 & 0.085 & 20 & 0.227 & 0.119 & 8 & 0.0013 & 0.464 \\
\hline & & L/dry & 34 & 5.47 & 0.555 & 0.065 & 20 & 0.221 & 0.143 & 8 & 0.0016 & 0.667 \\
\hline 9 & Pandowo Harjo & L/wet & 10 & 4.00 & 0.561 & 0.135 & - & - & - & - & - & - \\
\hline \multirow[t]{2}{*}{10} & Widodo Martani & L/wet & 18 & 3.82 & 0.559 & 0.024 & - & - & - & - & - & - \\
\hline & & A/dry & 24 & 3.98 & 0.548 & 0.029 & - & - & - & - & - & - \\
\hline 11 & Cokrodiningratan & L/dry & 40 & 5.54 & 0.538 & -0.005 & 19 & 0.226 & 0.094 & 9 & 0.0021 & 0.972 \\
\hline 12 & Tegal Panggung & L/dry & 40 & 5.47 & 0.543 & 0.039 & 20 & 0.227 & 0.102 & 13 & 0.0005 & 0.641 \\
\hline 13 & Mantrijeron & L/dry & 40 & 5.44 & 0.574 & 0.025 & 20 & 0.230 & 0.127 & 17 & 0.0004 & 0.721 \\
\hline
\end{tabular}

Indices for microsatellites, nuclear-genome wide SNPs and mitochondrial DNA sequences. $n$ sample size, $L$ larvae, $A$ adults, season: wet and dry; $H_{E}$ expected heterozygosity, $F_{\mathrm{IS}}$ inbreeding/fixation index, $\pi$ nucleotide diversity, $H_{\mathrm{d}}$ haplotype diversity

\section{Microsatellite typing}

Individuals were genotyped at nine microsatellite markers previously described (AC1, AG5, 88AT1, BbA10, BbH08, M201, 12ACG1, 470AG1 and 69TGA1 [25-27]). The loci were separated into three multiplex PCR assays as described in [28]. Microsatellite fragment separation analysis was conducted using the Applied Biosystems 96-capillary 3730xl DNA Analyser and GeneScan ${ }^{\text {tm }} 500$ LIZ $^{\circ}$ size standard and scored using GeneMarker ${ }^{\circ}$ Software Version 1.91 [29]. The final microsatellite dataset included: 152 adults and 351 larvae sampled across hamlets in wet season, and 320 larvae sampled from hamlets and inner city during dry season (Table 1).

\section{SNP typing}

Genome-wide single nucleotide polymorphism (SNP) genotyping was done using a customized double-digest RADseq method [30] as described in [19]. $100 \mathrm{ng}$ of genomic DNA from each larva was digested with 10 units of restriction enzymes NlaIII and MluCI (New England Biolabs, Beverly
MA, USA). Illumina adapters with customized barcode sequences (100 pM of P1, $300 \mathrm{pM}$ of P2) were ligated to the genomic fragments using 100 units of T4 ligase at $16{ }^{\circ} \mathrm{C}$ overnight (New England Biolabs, Beverly, MA, USA). Size selection of 300-450 bp long fragments was completed with the Pippin Prep protocol (Sage Sciences, Beverly, MA, USA). For the final library enrichment, five repeated PCR reactions with $1 \mathrm{nM}$ standard Illumina primers included the following cycling conditions: $98^{\circ} \mathrm{C}$ for $30 \mathrm{~s}, 12$ cycles of $98{ }^{\circ} \mathrm{C}$ for $10 \mathrm{~s}, 60^{\circ} \mathrm{C}$ for $30 \mathrm{~s}, 72{ }^{\circ} \mathrm{C}$ for $90 \mathrm{~s}$, and the final elongation at $72{ }^{\circ} \mathrm{C}$ for $5 \mathrm{~min}$. The independent reactions were pooled and purified to create a final library. Four libraries were sequenced in four lanes of Illumina HiSeq2000 using the $100 \mathrm{bp}$ paired-end chemistry (SRA Accession Numbers: SRP040064, SRX1425749).

Raw Illumina reads were filtered and trimmed based on a minimum phred score of 20 . We used the short read aligner program Bowtie [31] to align the filtered reads to the Ae. aegypti nuclear and mitochondrial reference genomes [32,33]. Because we expected our populations to 
show substantial genome divergence from the reference strain (i.e. Liverpool strain that originated from a West African population [32]), we allowed for the maximum number of mismatches in the alignment seed. The search algorithm was set to try as hard as possible to find valid alignments when they existed [Bowtie option-tryhard], and only uniquely aligned reads were then analysed with the Stacks pipeline [34]. Default program parameters were used for variant and likelihood-based genotype calling at RAD stacks that had a depth of at least five reads. The final RADseq dataset included 46 larvae collected across three hamlets in the wet season and 117 larvae collected from five hamlets and three inner city locations in the dry season (Table 1, Additional file 1: Table S1). 27 larvae from the wet season had more than $30 \%$ missing data for nuclear SNPs and were excluded from downstream analyses for this marker set.

\section{Analyses of genetic diversity and structure Nuclear markers}

Basic population genetic analyses such as observed and expected heterozygosity and tests for departure from Hardy-Weinberg equilibrium were carried out using GenAlEx v6.5 [35] and Fstat 2.9.3.2 [36]. We used the program FreeNA to test for the presence of null alleles at microsatellite loci that can bias the estimates of within-population diversity and population structure [37].

To estimate the level of spatio-temporal genetic structuring, we performed the hierarchical analysis of molecular variance (AMOVA) and post-hoc pairwise $F_{\mathrm{ST}}$ comparisons, treating each sampling location as an independent sample nested within season. Statistical significance was determined from 999 permutations using the program GenAlEx v6.5 [35].

Genetic structure was also inferred using the individualbased analysis implemented in the program STRUCTURE v2.3.4 [38, 39], that uses multi-locus genotypes to determine the number of genetic groups $(\mathrm{K})$ and assign individuals to those groups. The parameter set included: admixture model with the information on the sampling location and correlated allele frequencies among populations. The number of burn-ins was 250,000 for the microsatellite datasets and 50,000 for the SNP datasets, followed by as many MCMC steps. Estimations were made for $\mathrm{K}=1$ to $\mathrm{N}$, where $\mathrm{N}$ represents the number of sampling sites in a given season. The most likely number of clusters was determined using the maximum likelihood guideline by Pritchard [40] and the deltaK method by Evanno et al. [41] implemented with the program Structure Harvester [42]. We also used a multivariate method called discriminant analysis of principal components (DAPC) [43] implemented within the R package adegenet [44], to infer the number of genetic groups and the individual assignment to those groups.
Presence of isolation by distance (IBD) [45] between sampling groups was estimated using the matrices of pair-wise linearized $F_{\mathrm{ST}}$ values and the natural $\log$ of pairwise geographic distance between sites. IBD among individuals was tested using the matrix of unweighted squared genetic distances between individuals [46] and the natural log of pairwise geographic distance between individuals. Significance of the correlation between the matrices of genetic and geographic distances was determined using a Mantel test with 999 permutations in GenAlEx v6.5 [35]. The spatial autocorrelation analysis [46] with 999 permutations was executed in the same program. An estimate of effective population size, $\mathrm{Ne}$, was obtained using the two-sample temporal analysis method [47] as applied in NeEstimator 2.01 [48] for both microsatellite and SNP data at sites 6, 7 and 8. Generations sampled were set at 0 and 10 based on the length of time between the two field collections and estimated 15 generations per year in Yogyakarta. Waples' method [47] uses moments-based $F$ statistics and, in this case, the estimator Fs [49] was applied as it has been developed to provide unbiased estimates of $\mathrm{Ne}$ for multiple types of data sets including large panels of SNPs.

\section{Mitochondrial markers}

The analyses of the number of mitochondrial haplotypes $(N \mathrm{~h})$, nucleotide diversity $(\pi)$, haplotype diversity $(H \mathrm{~d})$, as well as the spatio-temporal AMOVA were done in the $\mathrm{R}$ package pegas [50]. We used $R^{2}$ test [51] for detecting population growth, determining the statistical significance with 1000 simulations of populations under the drift-mutation equilibrium in pegas [50]. The $R^{2}$ test has greater power than a classical mismatch distribution test for smaller sample sizes [51]. Haplotype network analysis with the statistical parsimony method was completed with the R package TempNet [52].

\section{Results}

\section{Nuclear diversity}

Allelic richness over nine microsatellite loci within each site ranged between 3.81 to 5.31 in wet season and between 5.14 and 5.81 in dry season (Table 1). Site 2 exhibited the highest allelic richness in both seasons. In general, observed heterozygosity at each sampling location was lower than expected heterozygosity (Table 1) and markers did not exhibit significant linkage disequilibrium.

After removing nuclear RAD tags with more than $30 \%$ of missing data, the final dataset included 3,178 polymorphic tags distributed across 830 scaffolds on all three chromosomes of Ae. aegypti. Overall nucleotide diversity in these RAD tags was 0.0023 . Because multiple SNPs within the same RAD tag are expected to be in nearly complete linkage disequilibrium, we retained only one SNP per tag. Expected heterozygosity across 3,178 
SNPs was similar for all sites, ranging between 0.205 and 0.230 , and was somewhat higher than the observed heterozygosity ( $F_{\text {IS }}$ from 0 to 0.157 , Table 1$)$.

\section{Nuclear genetic structure}

For both marker systems, hierarchical analysis of molecular variance (AMOVA) indicated strong spatial genetic structure that was temporally stable (Table 2 ). Three percent of total variation at microsatellite loci was attributed to differences in allele frequencies among sites within a season, while no significant variation could be attributed to changes across seasons. Spatial difference in frequencies of nuclear genome-wide SNPs contributed to nearly seven percent of total variation (Table 2). Pairwise $F_{\mathrm{ST}}$ comparisons at SNPs revealed that mosquitoes from sites 2 and 6 showed the highest differentiation at within the region (Table 3). Also, adult and larval samples collected within the same hamlet did not show a significant difference in allele frequencies, except at site 6 (Additional file 1: Table S1). Genome-wide SNPs revealed much lower differentiation among city sites than among hamlets, while microsatellite markers did not reveal this pattern (Table 3).

STRUCTURE analyses of adult mosquitoes suggested four genetic groups based on the highest likelihood of data, and two groups based on the deltaK method (Additional file 1: Table S2). For the larval samples, both methods indicated that the number of genetic groups was three in the wet season and two in the following dry season (Additional file 1: Table S2).

Genome-wide SNPs showed much greater power in distinguishing Ae. aegypti individuals from different sites in Yogyakarta than microsatellite markers (Fig. 2) and DAPC without prior information on the sampling location ('blind DAPC') revealed three genetic clusters in the

Table 2 Hierarchical analysis of molecular variance (AMOVA) with sites nested within seasons

\begin{tabular}{|c|c|c|c|c|c|}
\hline \multicolumn{6}{|c|}{ AMOVA Summary } \\
\hline \multicolumn{6}{|c|}{ nuclear SNPs } \\
\hline Source & df & SS & MS & Est. Var. & $\%$ \\
\hline season & 1 & 2447.806 & 2447.806 & 2.882 & 0.1 \\
\hline site & 6 & 13576.461 & 1939.494 & 36.268 & 6.8 \\
\hline Error & 318 & 160791.500 & 510.349 & 510.449 & 93.1 \\
\hline Total & 325 & 176815.767 & & 549.599 & 100.0 \\
\hline \multicolumn{6}{|l|}{ mtDNA } \\
\hline Source & df & SS & MS & Est. Var. & $\%$ \\
\hline season & 1 & 3.922 & 3.922 & 0.013 & 0.4 \\
\hline site & 6 & 21.663 & 3.610 & 0.095 & 4.6 \\
\hline Error & 131 & 257.207 & 1.963 & 1.963 & 95.0 \\
\hline Total & 138 & 282.791 & & 2.071 & 100.0 \\
\hline
\end{tabular}

Datasets include nuclear SNPs and mitochondrial DNA sequences from Aedes aegypti larvae from Yogyakarta, Indonesia
SNP dataset. Again, sites 2 and 6 showed greater separation from other sites in the region, while site 8 and inner city cites could not be distinguished. Moreover, temporal stability of genetic structure was demonstrated by the overlap of temporal samples in the PC space (Fig. 2).

Presence of IBD was highly supported between individual adult mosquitoes (microsatellites: Mantel $r=0.106, P<0.01$ ), and individual larvae in the season (microsatellites: Mantel $r=0.106, P<0.01$; SNPs: Mantel $r=0.247, P<0.01)$. Spatial autocorrelation analysis indicated that greater relatedness between pairs of larvae can be found at distances of 8-9 km, even though it is low for larvae from different sites (i.e. autocorrelation coefficient is significantly negative at distances 3-6 km) (Fig. 3).

Site 6 had the lowest estimated $\mathrm{Ne}$ out of the three sites tested, using either microsatellite or SNP data (Table 4). Tighter estimates of $\mathrm{Ne}$ for the SNP data are in line with the observation that current methods tend to produce intervals that are too narrow when a large number of markers is used [48]. $95 \%$ confidence intervals for Ne generated from SNP data were 128-144, 265-298 and 689-774, for Sites 6, 7 and 8 respectively (Table 4). For microsatellite data, estimates from the same sites were 212-564, infinite and 449-1303, respectively. Infinite value for the unbiased $\mathrm{Ne}$ estimator means that temporal genetic variation can be explained by the sampling error alone, and not by the effects of a finite number of parents [48].

\section{Mitochondrial diversity and structure}

We found 16 RAD tags in eight mitochondrial genes (ND2, COXI, COX3, ATP6, ND4-ND6, CYTB) that were present in more than $80 \%$ of individuals. We first checked for the presence of premature stop codons or heterozygous loci that would suggest paralogous/nuclear copies of mitochondrial sequences $[53,54]$ and then we concatenated all tags into sequences that were $990 \mathrm{bp}$ long. Additionally, we confirmed that in 14 individuals ddRAD tags had sequences identical to the longer amplicons from the corresponding mitochondrial regions [55]. Nevertheless, it is possible to have some spurious signals originating from the nuclear copies despite the control steps we employed in our study. There were 22 unique haplotypes in the full dataset (combined across sites and seasons), with haplotype 2 being shared among all eight sites, and haplotype 9 among five sites (Fig. 4). Haplotype diversity ranged between 0.250 and 0.972 and nucleotide diversity ranged between 0.0004 and 0.0044 (Table 1, Fig. 4). AMOVA revealed significant spatial structure after accounting for small seasonal changes of the mitochondrial haplotype frequencies (Table 2). The haplotype network for the entire dataset was star-shaped, with 
Table 3 Pair-wise $F_{\text {ST }}$ values for spatial and temporal samples of Aedes aegypti from Yogyakarta, Indonesia. Larvae were typed at nuclear SNPs (bellow diagonal) and microsatellite markers (above diagonal). Seasonal samples are designated with a bracket, e.g. sample from site 7 collected in the wet season is labeled as 7 (wet). Non-significant $F_{\text {ST }}$ values are shaded

\begin{tabular}{|c|c|c|c|c|c|c|c|c|c|c|c|}
\hline & $\mathbf{2}$ & $\mathbf{3}$ & $\mathbf{6}$ (wet) & $\mathbf{6}$ (dry) & $\mathbf{7}$ (wet) & $\mathbf{7}$ (dry) & $\mathbf{8}$ (wet) & $\mathbf{8}$ (dry) & $\mathbf{1 1}$ & $\mathbf{1 2}$ & $\mathbf{1 3}$ \\
\hline $\mathbf{2}$ & & 0.019 & 0.015 & 0.038 & 0.017 & 0.022 & 0.018 & 0.010 & 0.016 & 0.005 & 0.002 \\
\hline $\mathbf{3}$ & 0.081 & & 0.036 & 0.060 & 0.042 & 0.053 & 0.033 & 0.022 & 0.021 & 0.010 & 0.022 \\
\hline $\mathbf{6}$ (wet) & 0.120 & 0.086 & & 0.006 & 0.017 & 0.018 & 0.038 & 0.019 & 0.020 & 0.022 & 0.012 \\
\hline $\mathbf{6}$ (dry) & 0.125 & 0.093 & 0.029 & & 0.041 & 0.052 & 0.067 & 0.040 & 0.052 & 0.050 & 0.040 \\
\hline $\mathbf{7}$ (wet) & 0.115 & 0.061 & 0.064 & 0.069 & & -0.003 & 0.024 & 0.005 & 0.020 & 0.010 & 0.008 \\
\hline $\mathbf{7}$ (dry) & 0.112 & 0.060 & 0.052 & 0.058 & 0.017 & & 0.021 & 0.007 & 0.019 & 0.014 & 0.006 \\
\hline $\mathbf{8}$ (wet) & 0.162 & 0.099 & 0.138 & 0.142 & 0.042 & 0.053 & & 0.003 & 0.021 & 0.004 & 0.004 \\
\hline $\mathbf{8 ~ ( d r y )}$ & 0.157 & 0.094 & 0.134 & 0.141 & 0.038 & 0.049 & 0.008 & & 0.005 & -0.004 & -0.003 \\
\hline $\mathbf{1 1}$ & 0.160 & 0.096 & 0.130 & 0.136 & 0.036 & 0.043 & 0.015 & 0.017 & & 0.000 & 0.004 \\
\hline $\mathbf{1 2}$ & 0.150 & 0.085 & 0.120 & 0.129 & 0.034 & 0.040 & 0.015 & 0.015 & 0.009 & & -0.001 \\
\hline $\mathbf{1 3}$ & 0.156 & 0.092 & 0.129 & 0.135 & 0.038 & 0.045 & 0.009 & 0.013 & 0.011 & 0.011 & \\
\hline
\end{tabular}

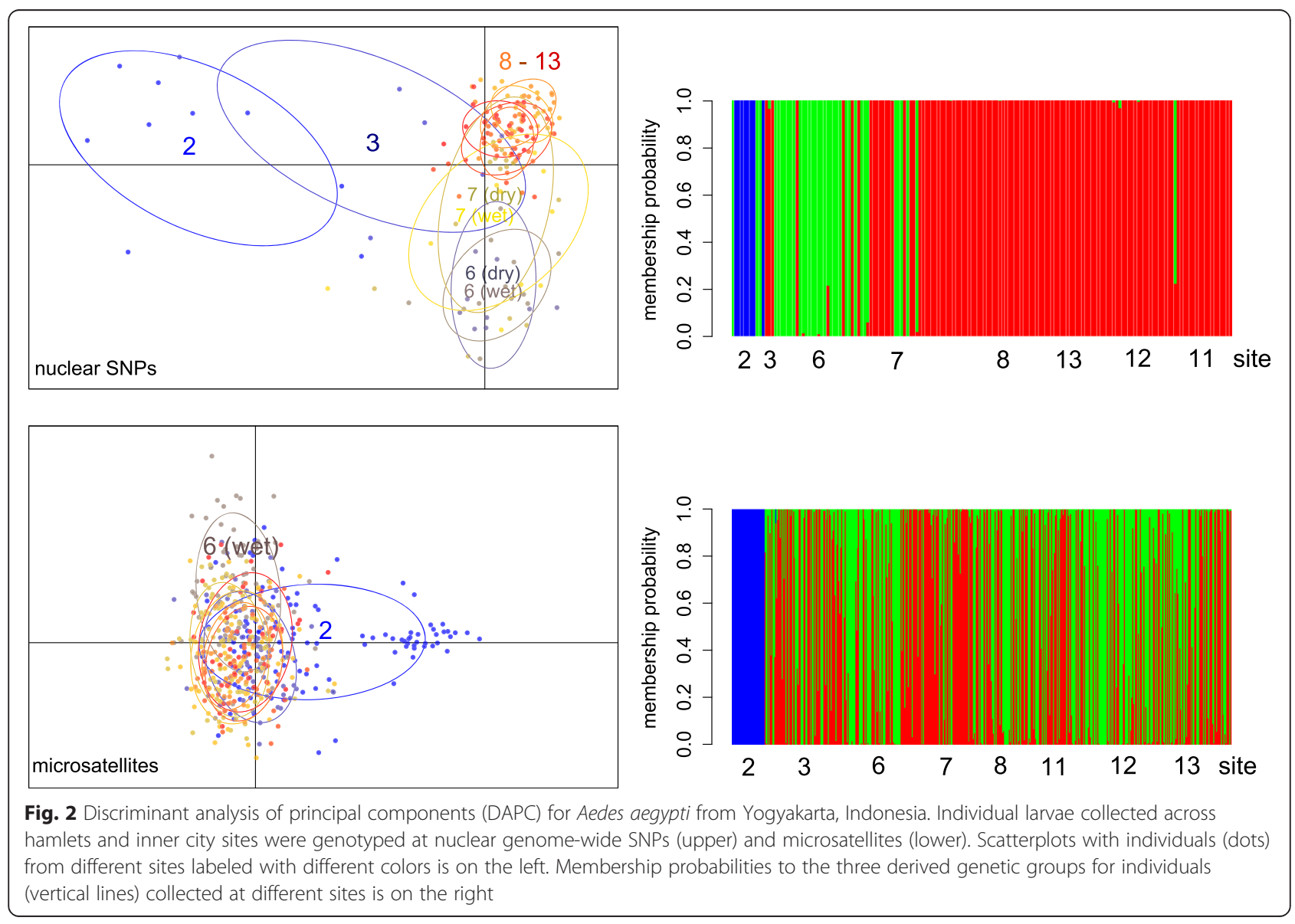




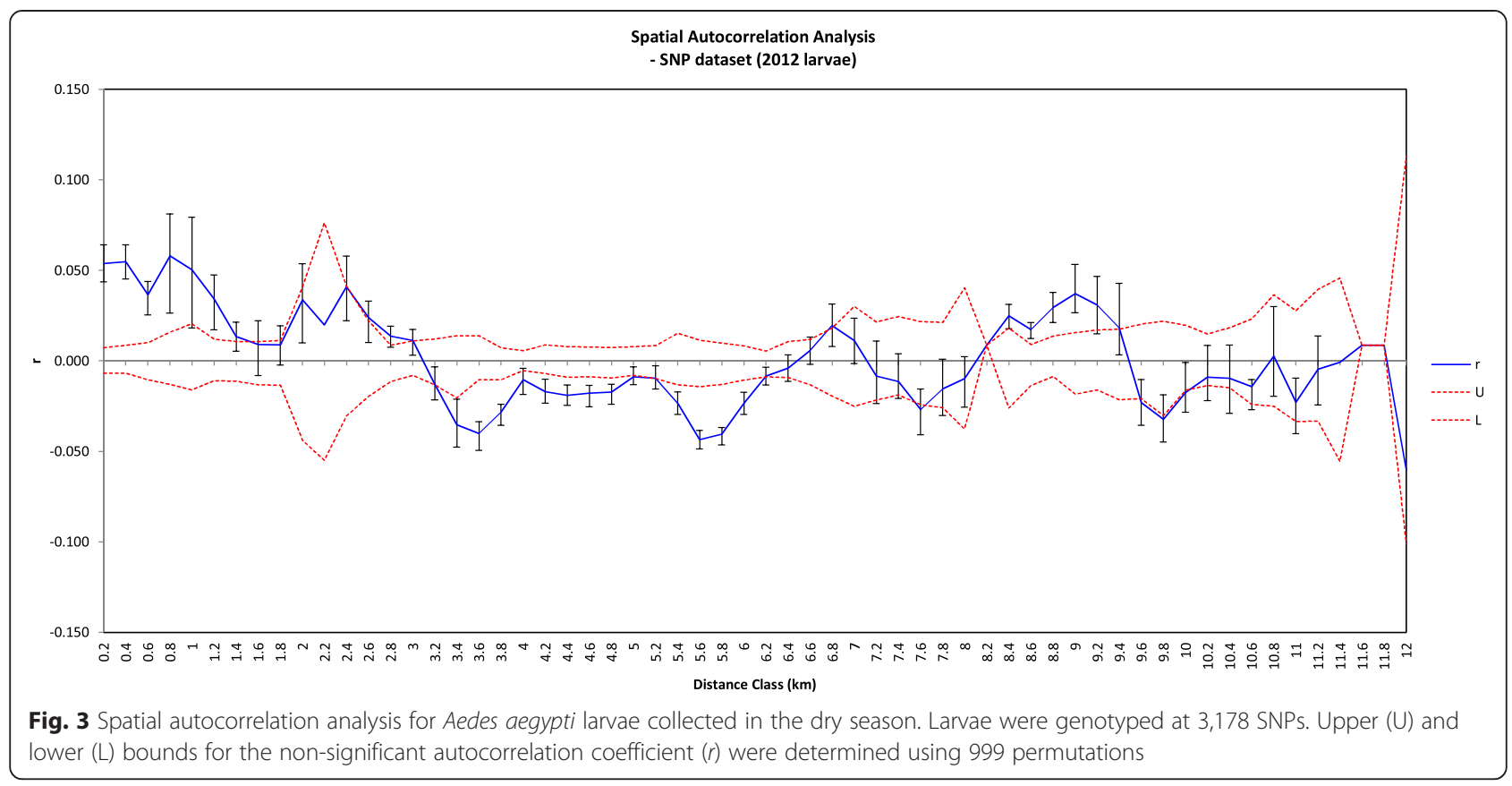

one predominant haplotype (haplotype 2) and pair-wise haplotype differences ranging between one and eight base pairs (Fig. 5). The star-shaped haplotype network suggests exponential population growth [56], and this hypothesis was supported with the $R^{2}$ test for recent population expan$\operatorname{sion}\left(R^{2}=0.0187, P=0.001\right)$.

\section{Discussion}

Multiple marker systems and temporal sampling of Aedes aegypti across Yogyakarta revealed that the dengue fever mosquito has spatially structured and seasonally stable populations in this region of Indonesia. Nuclear markers (genome-wide SNPs and microsatellites) showed that mosquitoes from some hamlets exhibit greater genetic isolation, regardless of their geographic position (e.g. sites
2 and 6). Also, mosquitoes from inner city sites and one hamlet (site 8) seem to interbreed freely, constituting a single genetic cluster. Mitochondrial variation suggests relatively recent population expansion of Ae. aegypti in this region.

Aedes aegypti is thought to have invaded southeast Asia from the New World as recently as the 20th century [57]. Mitochondrial data available in our study do not allow for identification of the origin of Ae. aegypti in Yogyakarta, but the presence of a single haplogroup supports the hypothesis of a small or genetically homogeneous source that underwent population expansion. This is in sharp contrast to Ae. aegypti from Rio de Janeiro, Brazil, where several highly divergent mitochondrial lineages have been found in one continuously

Table 4 Temporal estimates of effective population size (Ne) for Aedes aegypti from Yogyakrta, Indonesia

\begin{tabular}{|c|c|c|c|c|c|c|}
\hline \multirow{2}{*}{$\frac{\text { Site }}{\text { Marker type }}$} & \multicolumn{2}{|l|}{6} & \multicolumn{2}{|l|}{7} & \multicolumn{2}{|l|}{8} \\
\hline & msats & SNPS & msats & SNPS & msats & SNPS \\
\hline No. of independent alleles & 33 & 2104 & 28 & 2172 & 28 & 2286 \\
\hline Harmonic mean sample size & 35 & 8 & 42 & 12 & 34 & 19 \\
\hline Fs & 0.04222 & 0.16824 & 0.02079 & 0.10359 & 0.03595 & 0.05988 \\
\hline$F^{\prime}$ & 0.01363 & 0.03676 & -0.0032 & 0.0178 & 0.00609 & 0.00684 \\
\hline $\mathrm{Ne}$ & 367 & 136 & Infinite & 281 & 820 & 730 \\
\hline \multirow[t]{2}{*}{$95 \%$ Cls for $N_{e}$} & 212 & 128 & Infinite & 264 & 449 & 689 \\
\hline & 563 & 144 & Infinite & 298 & 1303 & 773 \\
\hline \multirow[t]{2}{*}{ Jackknife on loci } & 116 & 105 & 964 & 201 & 143 & 483 \\
\hline & Infinite & 192 & Infinite & 464 & Infinite & 1498 \\
\hline
\end{tabular}




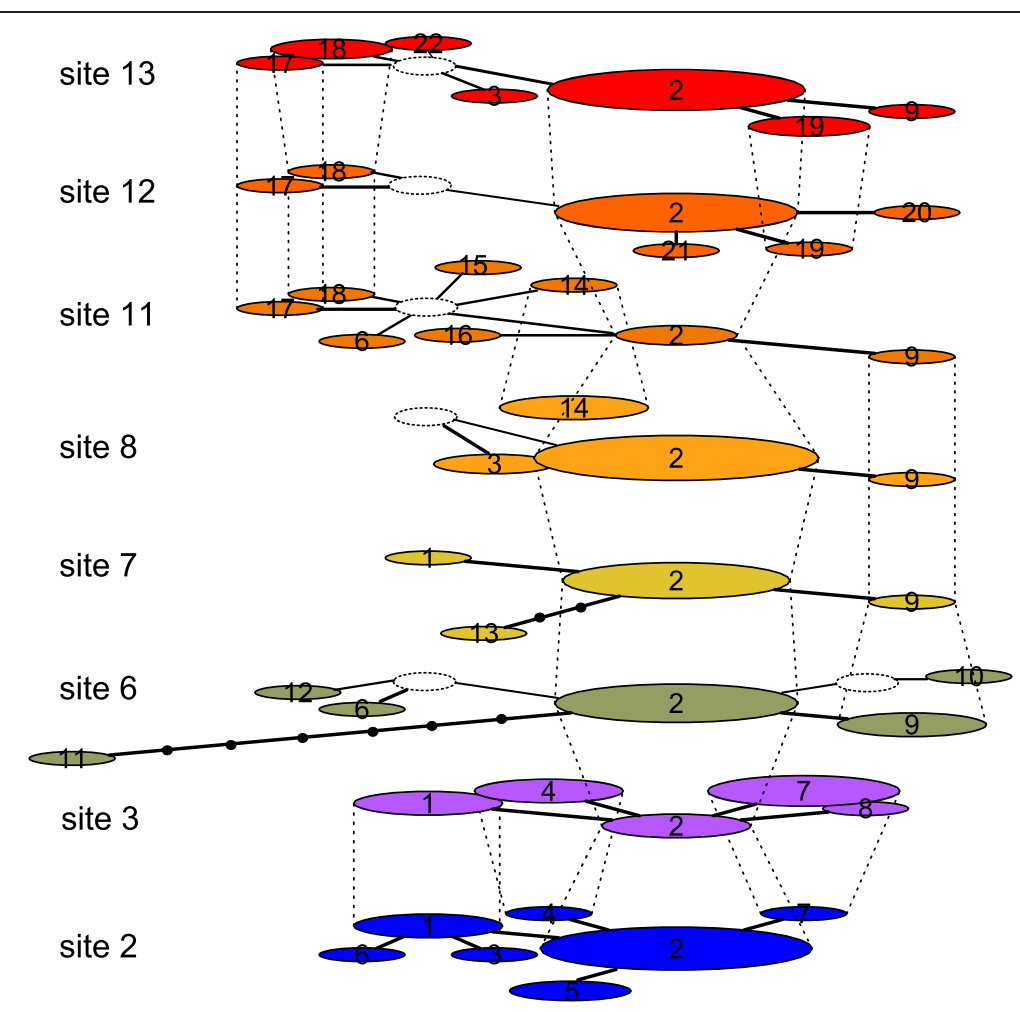

Fig. 4 Haplotype networks depicting spatial variation of mitochondrial haplotypes. Aedes aegypti samples were collected at 5 hamlets (sites 2,3,6-8) and 3 inner city sites (11-13) in Yogyakarta, Indonesia. Dotted vertical lines connect identical haplotypes found at different sites. Ellipse size corresponds to the number of individuals with a given haplotype. A number within an ellipse denominates the specific haplotype (1-22)

distributed large population [58]. Our results are consistent with previous reports of much lower genetic diversity in Ae. aegypti populations from southeast Asia when compared with those in the New World. For example, Bosio et al. [59] found that the dengue fever mosquito in Thailand harbors mitochondrial diversity that is $2-3$ times lower than that in Mexico.

Analyses of nuclear markers suggest stronger influence of human-assisted gene flow than active dispersal in shaping the spatial pattern of genetic structure in $A e$. aegypti from Yogyakarta. Genetic clustering did not clearly correspond to the spatial distance among sampling locations, resulting in a very weak isolation-bydistance. Generally, hamlets showed greater genetic isolation from each other and from the inner city sites. However, one hamlet (site 8) exhibited unrestricted interbreeding with mosquitoes from the inner city, forming a single genetic cluster. The spatial genetic structure of Ae aegypti in Indonesia parallels the examples from Thailand, where mosquitoes show overall

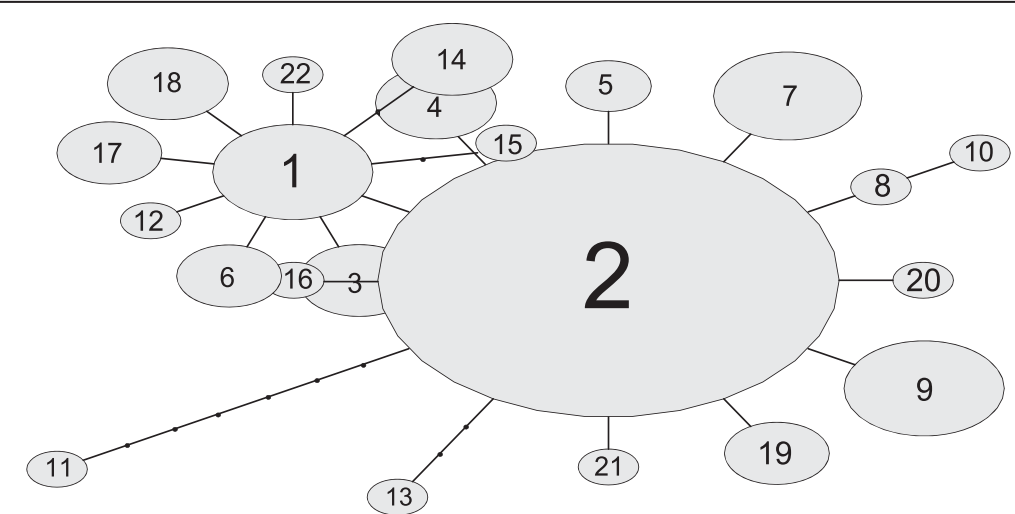

Fig. 5 Haplotype network depicting total variation of mitochondrial haplotypes in Aedes aegypti from Yogyakarta. A number within an ellipse designates a specific haplotype (1-22), with the ellipse size proportional to the number of individuals with a given haplotype 
weaker differentiation within urban areas such as Bangkok or Hat Yai than in suburban or rural areas $[60,61]$. Exceptions to these common patterns, like the case of high genetic connectivity between some hamlets and the urban center in Yogyakarta, could help identify specific human activities/means of transportation that facilitate extensive long distance gene flow in this mosquito.

A recent entomological study in Yogyakarta found that numbers of adult mosquitoes tended to fluctuate by season in sites 2 and 6 , but were stable throughout a year in sites 7 and 8 [62]. We did not detect any significant seasonal changes in genetic structure at site 6 , but the estimated effective population size was several times lower than in site 8. Some of the local variation in mosquito numbers may be attributed to differences in rainfall patterns that varied across hamlets [62]. Other factors could include locally varying mosquito control measures, such as removal of breeding habitats and application of insecticides which has been widespread in Indonesia since the 1970s [63]. However, our data suggest that local control measures have had little overall success in reducing mosquito numbers to levels that would cause significant genetic bottlenecks, as seen from a temporally stable genetic structure in populations of Ae. aegypti across Yogyakarta. Diminishing efficacy of insecticide-based mosquito control is seen globally due to rapidly evolving resistance to all classes of insecticides [64]. Recent results from bioassays and genetic screening of putative resistance alleles in Ae. aegypti demonstrated that pyrethroid insecticides are likely to be losing efficacy in Yogyakarta, urging the need for the employment of resistance management tactics [65]. Our insights into the genetic connectivity of mosquito populations should assist in predicting the spread of the resistance alleles in this region.

Knowledge of the spatio-temporal genetic diversity and structuring in Ae. aegypti from Yogyakarta obtained through our study is also useful for implementation of Wolbachia-based strategies in this region. Replacement of local mosquito populations with Wolbachia -infected mosquitoes could be more challenging in hamlet 8 and within the city sites due to high migration of uninfected mosquitoes into the release area. This could require a process of "adaptive management", where an increased rate of releases is undertaken in areas with slower Wolbachia invasion [15].

\section{Conclusion}

Our study provides the first insight into the genetic diversity and structure of the dengue fever mosquito, Aedes aegypti, in Indonesia where dengue is endemic. Seasonal stability of population genetic structure and diversity suggests limited effectiveness of traditional control measures to reduce numbers of breeding mosquitoes. Finally, knowledge of the genetic connectivity/isolation of mosquitoes in some parts of Yogyakarta will be useful for optimizing the strategy that involves the releases of Wolbachia-infected mosquitoes to suppress dengue transmission.

\section{Additional file}

Additional file 1: Table S1. Pairwise $F_{\text {ST }}$ comparisons between Aedes aegypti adults and larvae. Individuals collected in wet season were scored at nine microsatellite loci. Table S2. STRUCTURE Harvester results for adult and larval mosquitoes that were scored at nine microsatellite loci. (DOCX $19 \mathrm{~kb})$

\section{Competing interests}

The authors declare no competing interests.

\section{Authors' contributions}

GR processed and analysed the RADseq and microsatellite data, wrote the manuscript. NEH analysed the microsatellite data and wrote the manuscript. WT designed the field work and collected samples. AG and WW performed the microsatellite laboratory work and part of the data analysis. QY performed the RADseq laboratory work and data pre-processing. IF performed the RADseq data processing. PJ designed the field work and collected samples. AAH conceived the study and drafted the manuscript. EA designed and lead the field work and collections. All authors have read and approved the final manuscript.

\section{Acknowledgements}

This work is funded by the National Health and Medical Research Council, the Tahija Foundation and the Foundation for the National Institutes of Health through the Grand Challenges in Global Health Initiative of the Bill and Melinda Gates Foundation. Computational resources were provided by the NeCTAR Research Cloud at the University of Melbourne. The funders had no role in the study design, data collection, analyses and interpretation, or the manuscript writing.

\section{Author details}

${ }^{1}$ School of BioSciences, Bio21 Institute, The University of Melbourne, Melbourne, VIC 3010, Australia. '2Eliminate Dengue Project-Yogyakarta, Center for Tropical Medicine, Faculty of Medicine, Universitas Gadjah Mada, Yogyakarta, Indonesia. ${ }^{3}$ Eliminate Dengue Project, School of Biological Sciences, Monash University, Melbourne, VIC 3800, Australia.

Received: 19 October 2015 Accepted: 23 November 2015 Published online: 01 December 2015

\section{References}

1. World Health Organization. Dengue and severe dengue. WHO Fact Sheet 2012:1-4.

2. Karyanti MR, Uiterwaal CS, Kusriastuti R, Hadinegoro SR, Rovers MM, Heesterbeek $\mathrm{H}$, et al. The changing incidence of Dengue Haemorrhagic Fever in Indonesia: a 45-year registry-based analysis. BMC Infect Dis. 2014;14: 412.

3. Guzman MG, Halstead SB, Artsob H, Buchy P, Farrar J, Gubler DJ, et al. Dengue: a continuing global threat. Nat Rev Microbiol. 2010;8(12 Suppl):S7-16.

4. Harrington LC, Edman JD, Scott TW. Why do female Aedes aegypti (Diptera: Culicidae) feed preferentially and frequently on human blood? J Med Entomol. 2001;38:411-22.

5. Scott TW, Naksathit A, Day JF, Kittayapong P, Edman JD. A fitness advantage for Aedes aegypti and the viruses it transmits when females feed only on human blood. Am J Trop Med Hyg. 1997:57:235-9.

6. Service MW. Importance of ecology in Aedes aegypti control. Southeast Asian J Trop Med Public Health. 1992;23(4):681-90.

7. Mulyatno KC, Yamanaka A, Ngadino, Konishi E. Resistance of Aedes aegypti (L.) larvae to temephos in Surabaya, Indonesia. Southeast Asian J Trop Med Public Health. 2012;43:29-33. 
8. Ahmad I, Astari S, Tan M. Resistance of Aedes aegypti (Diptera: Culicidae) in 2006 to pyrethroid insecticides in Indonesia and its association with oxidase and esterase levels. Pakistan J Biol Sci. 2007;10:3688-92.

9. McGraw EA, O'Neill SL. Beyond insecticides: new thinking on an ancient problem. Nat Rev Microbiol. 2013;11:181-93.

10. McMeniman CJ, Lane RV, Cass BN, Fong AWC, Sidhu M, Wang Y-F, et al Stable introduction of a life-shortening Wolbachia infection into the mosquito Aedes aegypti. Science. 2009;323:141-4.

11. Xi Z, Khoo CCH, Dobson SL. Wolbachia establishment and invasion in an Aedes aegypti laboratory population. Science. 2005;310:326-8.

12. Moreira LA, Iturbe-Ormaetxe I, Jeffery JA, Lu G, Pyke AT, Hedges LM, et al. A Wolbachia symbiont in Aedes aegypti limits infection with dengue, Chikungunya, and Plasmodium. Cell. 2009;139:1268-78.

13. Walker T, Johnson PH, Moreira LA, Iturbe-Ormaetxe I, Frentiu FD, McMeniman CJ, et al. The wMel Wolbachia strain blocks dengue and invades caged Aedes aegypti populations. Nature. 2011;476:450-3.

14. Frentiu FD, Zakir T, Walker T, Popovici J, Pyke AT, van den Hurk A, et al. Limited Dengue Virus Replication in Field-Collected Aedes aegypti Mosquitoes Infected with Wolbachia. PLoS Negl Trop Dis. 2014:8:1-10.

15. Hoffmann AA, Montgomery BL, Popovici J, Iturbe-Ormaetxe I, Johnson PH, Muzzi F, et al. Successful establishment of Wolbachia in Aedes populations to suppress dengue transmission. Nature. 2011;476:454-7.

16. Hoffmann AA, Iturbe-Ormaetxe I, Callahan AG, Phillips BL, Billington K, Axford JK, et al. Stability of the wMel Wolbachia Infection following invasion into Aedes aegypti populations. PLoS Negl Trop Dis. 2014;8, e3115.

17. Hancock PA, Sinkins SP, Godfray HCJ. Population dynamic models of the spread of Wolbachia. Am Nat. 2011;177:323-33.

18. Barton NH, Turelli M. Spatial waves of advance with bistable dynamics: cytoplasmic and genetic analogues of allee effects. Am Nat. 2011;178:E48-75.

19. Rašić G, Filipović I, Weeks AR, Hoffmann AA. Genome-wide SNPs lead to strong signals of geographic structure and relatedness patterns in the major arbovirus vector, Aedes aegypti. BMC Genomics. 2014:15:275.

20. Hlaing T, Tun-Lin W, Somboon P, Socheat D, Setha T, Min S, et al. Spatial genetic structure of Aedes aegypti mosquitoes in mainland Southeast Asia. Evol Appl. 2010;3:319-39.

21. Urdaneta-Marquez L, Failloux A-B. Population genetic structure of Aedes aegypti, the principal vector of dengue viruses. Infect Genet Evol. 2011;11: 253-61.

22. Tana S, Umniyati S, Petzold M, Kroeger A, Sommerfeld J. Building and analyzing an innovative community-centered dengue-ecosystem management intervention in Yogyakarta, Indonesia. Pathog Glob Health 2012:106:469-78.

23. Apostol BL, Black WC, Reiter P, Miller BR. Use of Randomly Amplified Polymorphic DNA Amplified by Polymerase Chain-Reaction Markers to Estimate the Number of Aedes aegypti Families at Oviposition Sites in San-Juan, Puerto-Rico. Am J Trop Med Hyg. 1994;51:89-97.

24. Hoffmann AA, Goundar AA, Long SA, Johnson PH, Ritchie SA. Invasion of Wolbachia at the residential block level is associated with local abundance of Stegomyia aegypti, yellow fever mosquito, populations and property attributes. Med Vet Entomol. 2014;28 Suppl 1:90-7.

25. Chambers EW, Meece JK, McGowan JA, Lovin DD, Hemme RR, Chadee DD, et al. Microsatellite isolation and linkage group identification in the yellow fever mosquito Aedes aegypti. J Hered. 2007;98:202-10.

26. Slotman MA, Kelly NB, Harrington LC, Kitthawee S, Jones JW, Scott TW, et al. Polymorphic microsatellite markers for studies of Aedes aegypti (Diptera: Culicidae), the vector of dengue and yellow fever. Mol Ecol Notes. 2006;7:168-71.

27. Lovin DD, Washington KO, Hemme RR, Mori A, Epstein SR, Harker BW, et al. Genome-based polymorphic microsatellite development and validation in the mosquito Aedes aegypti and application to population genetics in Haiti. BMC Genomics. 2009:9:1-9.

28. Rašić G, Endersby NM, Williams C, Hoffmann AA. Using Wolbachia-based release for suppression of Aedes mosquitoes: Insights from genetic data and population simulations. Ecol Appl. 2014;24:1226-34

29. Holland MM, Parson W. GeneMarker ${ }^{\star}$ HID: A Reliable Software Tool for the Analysis of Forensic STR Data. J Forensic Sci. 2011;56:29-35.

30. Peterson BK, Weber JN, Kay EH, Fisher HS, Hoekstra HE. Double digest RADseq: an inexpensive method for de novo SNP discovery and genotyping in model and non-model species. PLoS One. 2012;7, e37135.

31. Langmead B, Trapnell C, Pop M, Salzberg SL. Ultrafast and memory-efficient alignment of short DNA sequences to the human genome. Genome Biol. 2009;10:R25.
32. Nene V, Wortman JR, Lawson D, Haas B, Kodira C, Tu ZJ, et al. Genome sequence of Aedes aegypti, a major arbovirus vector. Science. 2007;316: $1718-23$.

33. Behura SK, Lobo NF, Haas B, DeBruyn B, Lovin DD, Shumway MF, et al. Complete sequences of mitochondria genomes of Aedes aegypti and Culex quinquefasciatus and comparative analysis of mitochondrial dna fragments inserted in the nuclear genomes. Insect Biochem Mol Biol. 2011;41:770-7.

34. Catchen J, Hohenlohe PA, Bassham S, Amores A, Cresko WA. Stacks: An analysis tool set for population genomics. Mol Ecol. 2013;22:3124-40.

35. Peakall R, Smouse PE. GenALEx 6.5: Genetic analysis in Excel. Population genetic software for teaching and research-an update. Bioinformatics. 2012; 28:2537-9.

36. Goudet J. FSTAT: a computer program to calculate F-Statistics. J Hered. 2013;104:586-90.

37. Chapuis MP, Estoup A. Microsatellite null alleles and estimation of population differentiation. Mol Biol Evol. 2007;24:621-31.

38. Hubisz MJ, Falush D, Stephens M, Pritchard JK. Inferring weak population structure with the assistance of sample group information. Mol Ecol Resour. 2009;9:1322-32.

39. Falush D, Stephens M, Pritchard JK. Inference of population structure using multilocus genotype data: Linked loci and correlated allele frequencies. Genetics. 2003;164:1567-87.

40. Pritchard JK. Documentation for structure software: Version 2.3. In Pract. 2010;6:321-6.

41. Evanno G, Regnaut S, Goudet J. Detecting the number of clusters of individuals using the software STRUCTURE: A simulation study. Mol Ecol. 2005; 14:2611-20

42. Earl DA, vonHoldt BM. STRUCTURE HARVESTER: A website and program for visualizing STRUCTURE output and implementing the Evanno method. Conserv Genet Resour. 2012;4:359-61.

43. Jombart T, Devillard S, Balloux F. Discriminant analysis of principal components : a new method for the analysis of genetically structured populations. BMC Genet. 2010;11:94

44. Jombart T, Ahmed I. adegenet 1.3-1: new tools for the analysis of genome-wide SNP data. Bioinformatics. 2011;27:3070-1.

45. Wright S. Isolation by Distance. Genetics. 1943;28:114-38.

46. Smouse PE, Peakall R. Spatial autocorrelation analysis of individual multiallele and multilocus genetic structure. Heredity (Edinb). 1999;82(Pt5): 561-73

47. Waples RS. A generalized approach for estimating effective population size from temporal changes in allele frequency. Genetics. 1989;121:379-91.

48. Do C, Waples RS, Peel D, Macbeth GM, Tillett BJ, Ovenden JR. NeEstimator V2: Re-implementation of software for the estimation of contemporary effective population size (Ne) from genetic data. Mol Ecol Resour. 2014;14: 209-14.

49. Jorde PE, Ryman N. Unbiased estimator for genetic drift and effective population size. Genetics. 2007:177:927-35.

50. Paradis E. Pegas: An R package for population genetics with an integrated-modular approach. Bioinformatics. 2010;26(3):419-20.

51. Ramos-Onsins SE, Rozas J. Statistical properties of new neutrality tests against population growth. Mol Biol Evol. 2002;19:2092-100.

52. Prost S, Anderson CNK. TempNet: A method to display statistical parsimony networks for heterochronous DNA sequence data. Methods Ecol Evol. 2011; 2:663-7.

53. Black Iv WC, Bernhardt SA. Abundant nuclear copies of mitochondrial origin (NUMTs) in the Aedes aegypti genome. Insect Mol Biol. 2009;18:705-13.

54. Hlaing T, Tun-Lin W, Somboon P, Socheat D, Setha T, Min S, et al. Mitochondrial pseudogenes in the nuclear genome of Aedes aegypti mosquitoes: implications for past and future population genetic studies. BMC Genet. 2009;10:11.

55. Yeap HL, Rašić G, Endersby-Harshman NM, Lee SF, Arguni E, Le Nguyen H, et al. Mitochondrial DNA variants help monitor the dynamics of Wolbachia invasion into host populations. Heredity (Edinb). 2015. doi:10.1038/hdy.2015. 97.

56. Slatkin M, Hudson RR, Marjoram P, Donnelly P. Pairwise comparisons of mitochondrial DNA sequences in subdivided populations. Genetics. 1994; 136:673-83.

57. Brown JE, Evans BR, Zheng W, Obas V, Barrera-Martinez L, Egizi A, et al. Human impacts have shaped historical and recent evolution in Aedes aegypti, the dengue and yellow fever mosquito. Evolution (NY). 2013;68:514-25. 
58. Rašić $G$, Schama R, Powell R, Maciel-de Freitas R, Endersby-Harshman NM, Filipović I, et al. Contrasting genetic structure between mitochondrial and nuclear markers in the dengue fever mosquito from Rio de Janeiro: implications for vector control. Evol Appl. 2015;8:901-15.

59. Bosio CF, Harrington LC, Jones JW, Sithiprasasna R, Norris DE, Scott TW. Genetic structure of Aedes aegypti populations in Thailand using mitochondrial DNA. Am J Trop Med Hyg. 2005;72:434-42.

60. Olanratmanee P, Kittayapong P, Chansang C, Hoffmann AA, Weeks AR, Endersby NM. Population genetic structure of Aedes (Stegomyia) aegypti (L.) at a micro-spatial scale in Thailand: implications for a dengue suppression strategy. PLoS Negl Trop Dis. 2013;7:e1913.

61. Sukonthabhirom S, Rongnoparut P, Saengtharatip S, Jirakanjanakit N, Chareonviriyaphap T. Genetic structure and gene flow among Aedes aegypti(Diptera: Culicidae) populations from central Thailand. J Med Entomol. 2005:42:604-9.

62. Tantowijoyo W, Arguni E, Johnson P, Budiwati N, Nurhayati Pl, Fitriana I, et al. Spatial and temporal variation in Aedes aegypti and Aedes albopictus numbers in the Yogyakarta area of Java, Indonesia, with implications for Wolbachia releases. J Med Entomol 2015 (in press).

63. Kusriastuti $R$, Sutomo $S$. Evolution of dengue prevention and control program in Indonesia. Dengue Bull. 2005;29:1-7.

64. Liu N. Insecticide Resistance in Mosquitoes: Impact, Mechanisms, and Research Directions. Annu Rev Entomol. 2015;60:537-59.

65. Rochmijati Wuliandari J, Lee SF, White VL, Tantowijoyo W, Hoffmann AA, Endersby-Harshman NM. Association between Three Mutations, F1565C, V1023G and S996P, in the Voltage-Sensitive Sodium Channel Gene and Knockdown Resistance in Aedes aegypti from Yogyakarta, Indonesia. Insects. 2015;6(3):658-85.

\section{Submit your next manuscript to BioMed Central and we will help you at every step:}

- We accept pre-submission inquiries

- Our selector tool helps you to find the most relevant journal

- We provide round the clock customer support

- Convenient online submission

- Thorough peer review

- Inclusion in PubMed and all major indexing services

- Maximum visibility for your research 